\title{
An almond-enriched diet improves biomarkers of cardiometabolic health and increases alertness without changing cognitive performance in older overweight adults
}

\author{
$\underline{\text { Alison Coates }}^{1}$, Samantha Morgillo $^{1}$, Catherine Yandell ${ }^{1}$, Andrew Scholey ${ }^{2}$, Jonathan Buckley $^{1}$ \\ and Alison Hill ${ }^{1}$ \\ ${ }^{1}$ University of South Australia, Adelaide, Australia and \\ ${ }^{2}$ Swinburne University, Melbourne, Australia
}

\begin{abstract}
Longitudinal studies report that regular nut consumption is associated with reduced risk of coronary heart disease and better cognitive function. Thus, nuts may improve cardiovascular and neurocognitive health - especially in 'at-risk' populations (e.g. overweight/ obese). This study examined the effect of supplementing habitual diets of overweight/obese individuals for 12 weeks with either almonds or carbohydrate rich (CHO-rich) snack foods on biomarkers of cardiovascular and metabolic health, mood and cognitive performance. Participants $(n=151$; overweight/obese, 50-80 years) were randomised to replace $15 \%$ energy intake with either almonds (Almond) or isocaloric CHO-rich snack foods (Comparator). Body weight, blood lipids, glucose, insulin, blood pressure (BP), arterial stiffness, mood and cognitive performance (memory, executive function, speed of processing) were measured at baseline and 12 weeks. One hundred and twenty eight participants $(78 \mathrm{~F}: 50 \mathrm{M}, \mathrm{n}=63$ almond, $\mathrm{n}=65$ control) completed the intervention $(\mathrm{M} \pm$ SD: age $64 \pm$ 8years, BMI $30.3 \pm 3.6 \mathrm{~kg} / \mathrm{m}^{2}$, stable medication use: $32 \%$ BP and $19 \%$ lipid lowering). Compared with the CHO-rich comparator foods, there were a number of significant improvements associated with almond consumption. These included reduced serum triglycerides $(\mathrm{M} \pm \mathrm{SEM}$, almond: $1.30 \pm 0.062$ to $1.16 \pm 0.062 \mathrm{mmol} / \mathrm{L}$ vs $\mathrm{CHO}$-rich $1.13 \pm 0.061$ to $1.17 \pm 0.061 \mathrm{mmol} / \mathrm{L}, \mathrm{p}$ $=0.005$ whole population). In those with cholesterol below the ATPIII cut point of $<6.2 \mathrm{mmol} / \mathrm{L}$ ( $84 \%$ of sample), almond consumption reduced total cholesterol (almond: $5.12 \pm 0.13$ to $4.93 \pm 0.12 \mathrm{mmol} / \mathrm{L}$ vs CHO-rich $5.24 \pm 0.13$ to $5.21 \pm 0.11 \mathrm{mmol} / \mathrm{L}, \mathrm{p}<0.001$ ) and LDL-cholesterol (almond: $3.03 \pm 0.11$ to $2.87 \pm 0.11 \mathrm{mmol} / \mathrm{L}$ vs $\mathrm{CHO}$-rich $2.98 \pm 0.10$ to $3.07 \pm 0.10 \mathrm{mmol} / \mathrm{L}, \mathrm{p}=0.002$ ). . Additionally in a non-BP medicated subgroup only $(\mathrm{n}=87,68 \%$ of sample), there was a reduction in systolic BP (almond: 130.73 \pm 2.19 to $127.02 \pm 2.19 \mathrm{mmHg}$ vs control: $128.63 \pm 2.32$ to $129.48 \pm 2.32 \mathrm{mmHg}, \mathrm{p}=0.035$; and improved self-rated alertness (almond $54.73 \pm 2.32$ to $58.64 \pm 2.32$ vs CHO-rich $61.75 \pm 2.28$ to $61.13 \pm 2.28, \mathrm{p}=0.048)$. The inclusion of almonds in the diet has the ability to improve aspects of cardiometabolic health and mood in overweight/obese adults. The lack of change in cognitive performance may reflect the fact that the study population was cognitively high performing at baseline. Future research should be directed at examining the effects of this relatively simple, cost-effective nutritional intervention in populations at greater risk of cardiometabolic and cognitive decline.
\end{abstract}

\section{Conflict of Interest}

This work was funded by the Almond Board of California 